\title{
Integrated method of petroleum products demand forecasting considering economic, demographic and technological factors
}

\author{
Tatiana Mitrova ${ }^{1} \bullet$ Vyacheslav Kulagin ${ }^{1,2} \bullet G^{\prime}$ Gushevenko Dmitriy ${ }^{1,2} \bullet$ Ekaterina \\ Grushevenko $^{1 *}$ • Anna Galkina ${ }^{1}$ \\ ${ }^{1}$ Oil and Gas Department, Energy Research Institute of the Russian Academy of Sciences (ERI RAS), Russia \\ ${ }^{2}$ Energy Institute, National Research University Higher School of Economics (HSE), Russia
}

\begin{abstract}
The article describes the new methodology for forecasting demand for petroleum products and specific groups of petroleum products globally and in various countries (nodes) and the results of its application for petroleum products demand forecasting in Russia. The developed methodology incorporates various forecasting approaches: correlation, factor forecasting, technical, economic and econometric analysis with elements of economic and mathematical modelling. This methodology may be used for a wide range of tasks, including markets forecasts for specific petroleum products, e.g., jet fuel or gasoline and integrated analysis of the world oil market development prospects and the future role of petroleum products in the energy balance of individual countries and regions.
\end{abstract}

Keywords: petroleum products, demand forecast, diesel, gasoline, jet fuel, alternative fuel JEL Classification Codes: E27, Q31, Q39, Q47

\section{Introduction}

Petroleum products (PP) demand forecasting is of great importance for the analyses of the oil market development. Historically inter-fuel competition in the transport sector-main area of PP consumption - was limited, so it was possible to use simple methodologies for PP demand forecasting. But as the global energy market is becoming increasingly diversified, technological development sets out new conditions, and the number of PP alternatives is growing. These market changes are reflected in many studies: IEA (2014), Mitrova, Galkina (2013), Schremp, Bahrenian, Weng-Gutierrez (2010). All these factors require new PP demand forecasting

\footnotetext{
* Corresponding author. E-mail: e.grushevenko@gmail.com.

Citation: Mitrova, T., Kulagin, V., Dmitriy, G., Grushevenko, E. and Galkina, A. (2015) Integrated method of petroleum products demand forecasting considering economic, demographic and technological factors, Economics and Business Letters, 4(3), 98-107.
} 
methods, taking into account these changes in the market. The article discusses a new approach to PP demand forecasting, which includes the analysis of economic, demographic and technological factors.

\section{Methodology}

Existing methods of PP demand forecasting may be traced to two fundamental approaches (Table 1):

- Forecasting of PP demand as a function of macroeconomic variables (top-down approach). It is described in the studies of Nakanishi (2006), Kugelevičius and Kuprys (2007), Chai, Wang, Guo (2012), Grushevenko (2012), Wang, Huo, Johnson, He (2006), Grigoriev, Kurdin (2013). The relation of energy consumption dynamics to macroeconomic variables dynamics is traditionally calculated by using regression and simulation models. Heuristic search algorithms, such as Behrang et al. (2011), genetic programming (Forouzanfar et al., 2012) etc. may also be used. Usually this approach analyzes dynamics of the GDP petroleum intensity. For example, jet fuel demand could be forecasted as a function of the cargo carriage volume, which is in its turn related to GDP dynamics (Cheze et al., 2011). (Cheze et al., 2011), may be analyzed. A key disadvantage of this approach is that it does not account for changes in technological development and consumer preferences. It also offers limited possibilities for analyzing inter-fuel competition and separating out demand within various consumption sectors. Moreover, in some countries energy consumption dynamics has lost its close relationship with GDP dynamics in recent decades (Cleveland et al., 2000).

- PP demand forecasting using multiple factors in the calculation (like car fleet, its structure, technical and economic parameters, etc.). This approach is used in IEA $(2011,2014)$, DOE (2014) and WEC (2011) models. The main issue with using this method is that it requires extremely detailed input information, and also the difficulty of reconciling calculations of transport sector demand with the PP demand in the other sectors. This method was analyzed by Bouachera and Mazraati (2007). Typically, these models are used in the analysis of a limited number of countries for which this information is available. A common simplification in this respect is the aggregation of countries being analyzed (Button et al., 1993). Difficulties with forecasting PP demand in the developing countries were analyzed by Bhattacharyya and Timilsina (2009).

The methodology of PP demand forecasting, developed in this study, not only includes these both approaches and combines them, but also significantly expands them by considering a greater number of factors, using clustering analysis and reconciling algorithms. This new approach increases accuracy of projections. The developed methodology is based on the combination of different forecasting approaches: correlation, factor, technical, economic and econometric analysis and modelling. It considers both determined correlational interdependencies between macroeconomic parameters and PP demand, as well as indicators reflecting technological improvements of vehicles and specifics of motor fuel consumption in selected countries/nodes. Since the developed methodology combines various PP demand forecasting approaches and uses their most effective elements, it actually combines the strong points of the top-down and bottom-up methods and minimizes their weaknesses.

This new methodology is designed to determine PP demand by different groups of end users. The results may be reported both as overall PP demand or as demand for separate large groups of PP. The following groups are used for calculations in accordance with consumer characteristics of individual fractions: 

1. Petroleum gases (LPG)
2. Naphtha
3. Gasoline
4. Jet fuel
5. Diesel
6. Fuel oil and other

The methodology may be used to perform a wide range of tasks:

- specific PP market forecasting;

- analyzing development prospects for the world oil market;

- assessing the future role of PP in the energy balance of individual countries and regions.

Table 1. Advantages and disadvantages of the different methodologies of PP demand forecasting.

\begin{tabular}{|c|c|c|c|}
\hline Advantage/disadvantage & Top-down approach & Bottom-up approach & The proposed methodology \\
\hline $\begin{array}{l}\text { Variability of calcula- } \\
\text { tions, the possibility to } \\
\text { take into account multi- } \\
\text { ple factors, the forecast } \\
\text { is not linked to macroe- } \\
\text { conomic indicators } \\
\text { solely. }\end{array}$ & $\begin{array}{l}\text { Usually the forecast } \\
\text { is completely de- } \\
\text { pendent on the pre- } \\
\text { sumed correlation of } \\
\text { PP demand and GDP } \\
\text { and population }\end{array}$ & Yes & Yes \\
\hline $\begin{array}{l}\text { Statistical data needed } \\
\text { for calculations is avail- } \\
\text { able and easily collected }\end{array}$ & $\begin{array}{l}\text { Since there are not } \\
\text { many input parame- } \\
\text { ters, they are mostly } \\
\text { available }\end{array}$ & $\begin{array}{l}\text { Data availability is } \\
\text { always a problem }\end{array}$ & $\begin{array}{l}\text { The countries are clustered } \\
\text { according to multiple crite- } \\
\text { ria to search for common } \\
\text { patterns, making it possi- } \\
\text { ble to resolve the problem } \\
\text { of insufficient information } \\
\text { using cluster characteris- } \\
\text { tics. }\end{array}$ \\
\hline $\begin{array}{l}\text { Possibility to calculate } \\
\text { PP demand by specific } \\
\text { sector }\end{array}$ & $\begin{array}{l}\text { This method does } \\
\text { not allow to identify } \\
\text { PP demand by sector } \\
\text { or it may be based } \\
\text { solely on the eco- } \\
\text { nomic performance } \\
\text { indicators of the sec- } \\
\text { tor (GDP in the sec- } \\
\text { tor) }\end{array}$ & $\begin{array}{l}\text { This methodology is } \\
\text { typically used to fore- } \\
\text { cast demand in the } \\
\text { transport sector only. } \\
\text { It is necessary to rec- } \\
\text { oncile the results with } \\
\text { the other consump- } \\
\text { tion sectors in other } \\
\text { models in order to de- } \\
\text { termine overall PP } \\
\text { demand. }\end{array}$ & $\begin{array}{l}\text { This methodology is com- } \\
\text { bining the «top-down» ap- } \\
\text { proach in assessing overall } \\
\text { petroleum demand and the } \\
\text { «bottom-up» approach in } \\
\text { assessing demand for mo- } \\
\text { tor fuel, with a subsequent } \\
\text { reconciliation of the re- } \\
\text { sults. }\end{array}$ \\
\hline $\begin{array}{l}\text { It is possible to take into } \\
\text { account inter-fuel com- } \\
\text { petition between PP and } \\
\text { other energy sources }\end{array}$ & $\begin{array}{l}\text { Inter-fuel competi- } \\
\text { tion is typically ac- } \\
\text { counted for rather } \\
\text { formally, by consid- } \\
\text { ering price elasticity }\end{array}$ & $\begin{array}{l}\text { This methodology } \\
\text { may contain technical } \\
\text { and economic indica- } \\
\text { tors, which are used } \\
\text { to account for inter- } \\
\text { fuel competition. }\end{array}$ & $\begin{array}{l}\text { «Bottom-up» instruments } \\
\text { are used to account for in- } \\
\text { ter-fuel competition in the } \\
\text { transport sector. Competi- } \\
\text { tion in the other sectors } \\
\text { may be accounted for } \\
\text { when other models are } \\
\text { used alongside (the authors } \\
\text { used the SCANER model- } \\
\text { ling complex). }\end{array}$ \\
\hline
\end{tabular}


Figure 1. Structure of the PP demand forecasting methodology, proposed by the authors.

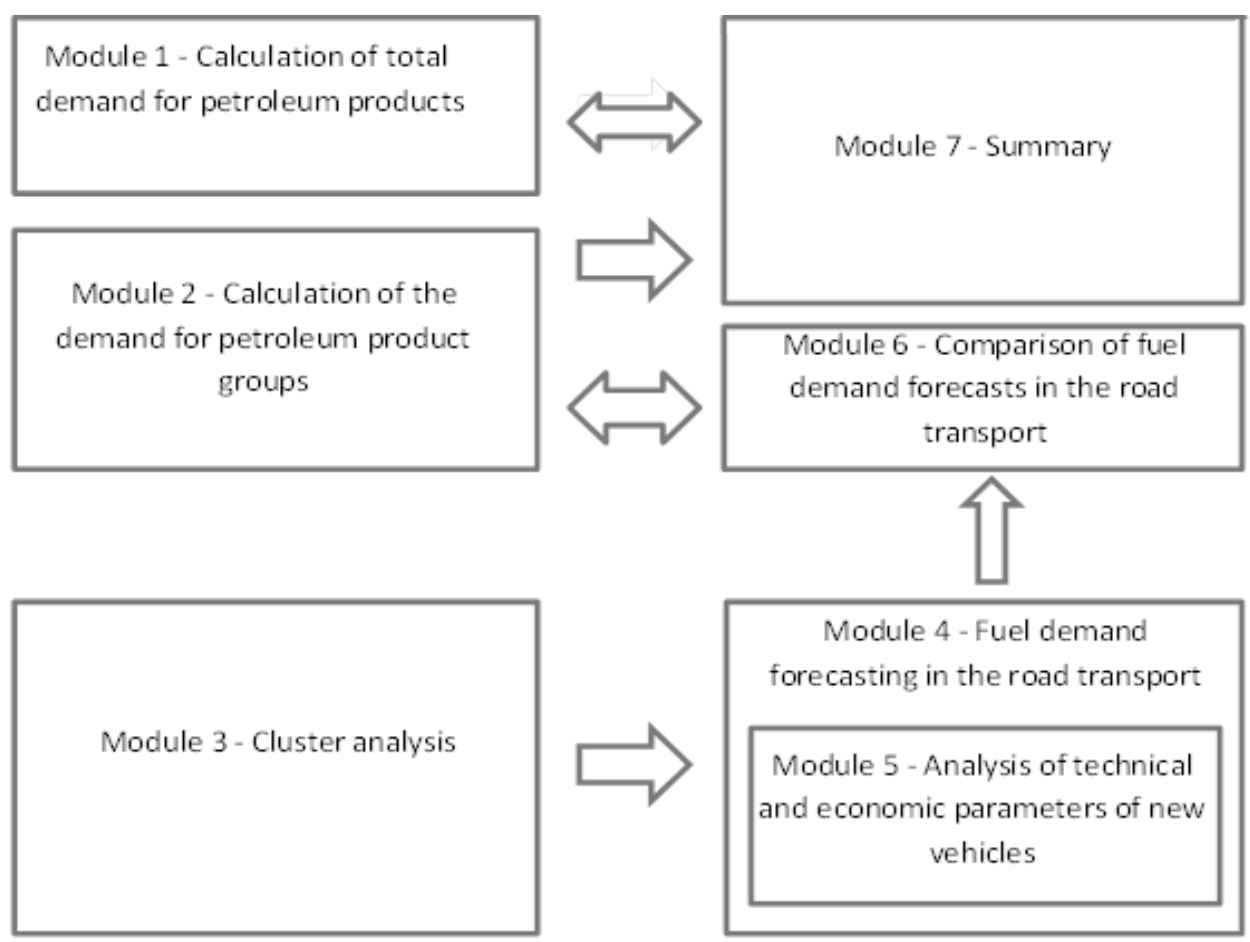

The described methodology has already been tested at ERI RAS. It was used as part of a larger SCANER modelling complex (Makarov et al., 2011) and it enabled to reconcile oil market forecasts with projections for other energy markets. The results of these calculations were used in the "Global and Russian Energy Outlook Up To 2040" (Makarov et al., 2013, 2014), and in the new Energy Strategy of the Russian Federation.

The methodology and its interrelationship with the other resource modules within the modelling complex allow to consider inter-fuel competition given various prices of energy resources competing with PP. This enables to determine long-term price elasticity of PP demand. Overall, three unique elements are used in the developed methodology, which differentiate it from other alternatives:

1. The methodology utilizes multi-criteria clustering approach to resolve the issue of the lack of information for individual countries.

2. It combines both the "top-down" and "bottom-up" approaches to resolve the issue of reconciling projected PP demand in the transport and other sectors.

3. It was developed as a part of an integrated system for global energy sector forecasting, enabling to take into account various factors in related sectors, which are affecting PP demand.

This methodology contains seven modules (Figure 1). The calculation algorithm in each Module is shown below. For module 1:

1. Correlation analysis of historical PP consumption rates, GDP and population are made. Correlation coefficients are determined to be used as weights in the formula for calculating overall projected PP demand.

2. Ratio of PP consumption to GDP (PP intensity) and the ratio of PP consumption to population (per capita consumption) are determined based on historical data. A trend for each (linear, exponential or logarithmic) is plotted.

3. Exogenous projected GDP and population data is used in the resulting trend equations. Thus, two PP demand projections are determined. 
4. Resulting PP demand projection is calculated based on projected GDP and population data, considering the weight of each parameter obtained by correlation analysis. The results are presented in energy equivalent.

Formula, used to project overall demand for each node in Module 1, is shown below (Eq. 1):

$$
\begin{aligned}
& \text { PPdemand }_{i} \\
& =\frac{\left(k \times \text { PPintensityGDP }_{i} \times G D P_{i}\right)+\left(m \times \text { PPdemandpercapita }_{i} \times \text { Population }_{i}\right)}{(k+m)}
\end{aligned}
$$

where:

PPdemand $_{i}$ - projected demand for all PP;

$i-$ year;

$k$ - correlation coefficient of total PP consumption to GDP in the node;

$P$ Pintensity $G D P_{i}-$ GDP PP intensity value;

$G D P_{i}-\mathrm{GDP}$ value;

$m$ - correlation factor of overall consumption of PP to population in the node;

PPdemandpercapita ${ }_{i}$ - per capita consumption of PP;

Population $_{\text {- population size. }}$

The algorithm in Module 2 is similar to Module 1, but the calculations are made for each product group in metric tonnes, after which they are added up to generate overall demand and converted into energy equivalent using conversion coefficients.

The results of Modules 1 and 2 do not make it possible to fully account for the current and future technological changes: introduction of alternative fuel vehicles, improving the efficiency of conventional vehicles (ERI RAS (2013). To solve this problem, demand for specific groups of PP - gasoline, competing fossil fuels (LPG, diesel) and non-petroleum fuels (electricity, natural gas) is calculated in Modules 4, 5. The calculations are made for the road transport sector (cars and trucks). According to the IEA (2013), this sector consumes $70 \%$ of all motor fuels, and all of the gasoline.

\begin{tabular}{|c|c|}
\hline Module No. & Module description \\
\hline Module 1 & $\begin{array}{l}\text { Total projected demand for PP is determined for each node depending on GDP and pop- } \\
\text { ulation dynamics. }\end{array}$ \\
\hline Module 2 & $\begin{array}{l}\text { Overall consumption of PP is determined by splitting projected total PP demand into } \\
\text { PP groups demand. }\end{array}$ \\
\hline Module 3 & Country nodes are grouped into clusters. \\
\hline Module 4 & $\begin{array}{l}\text { Fuel demand is determined for the road transport sector, including petroleum and non- } \\
\text { petroleum. The Module is based on the indicators which reflect the size and the structure } \\
\text { of the car fleet, as well as the indicators reflecting the technology and consumer prefer- } \\
\text { ences for specific motor fuels. Module } 4 \text { includes a separate unit of technical parameters } \\
\text { for new vehicles (Module 5). }\end{array}$ \\
\hline Module 5 & $\begin{array}{l}\text { Projected costs of vehicle ownership and their attractiveness to consumers are calculated } \\
\text { based on the economic and technical parameters of vehicles operating on various types } \\
\text { of fuel and their envisioned modernization. Consumer preferences and access to infra- } \\
\text { structure are also taken into account in the calculations. }\end{array}$ \\
\hline Module 6 & $\begin{array}{l}\text { Comparison of the results generated by Modules } 4 \text { and 2. Projected GDP PP intensity } \\
\text { and per capita consumption of gasoline, diesel fuel and LPG are adjusted within Module } \\
2 \text { based on this comparison. }\end{array}$ \\
\hline Module 7 & Iteration process of reconciliation of the results from Modules 1 and 2. \\
\hline
\end{tabular}

Table 2. Purpose of each module. 
There is a large number of countries and indicators used in this modelling. The methodology therefore envisions cluster analysis, taking place in Module 3, in order to summarize some of the indicators. In this analysis, groups of countries with similar characteristics are differentiated.

Clustering is performed by k-means method according to three key indicators describing the node: per capita GDP, net exports of oil and PP, ratio of diesel and gasoline in motor fuel consumption (Grushevenko, 2014). According to these analysis, all countries were divided into seven clusters:

1. USA is a major energy producer and consumer;

2. The largest oil exporters: Saudi Arabia and Russia;

3. The largest developing economies: China and India;

4. Developed major large economies (Germany, Spain, Italy, France, Japan, Korea);

5. Large oil and PP producing countries;

6. Some European countries, CIS countries and South America;

7. The least developed economies.

Cluster analysis is used to aggregate several projected indicators used in the calculations of Modules 4 and 5 for all nodes in the cluster, depending on the indicators of the representative cluster.

Module 4 calculates future demand for motor fuel as a function of several parameters for each node (Eq. 2):

$$
D M F_{i, j}=V_{i, j} \times M_{i, j} \times F_{i, j}
$$

where:

$i$ - year;

$j$ - motor fuel type;

$D M F$ - motor fuel demand;

$V$ - fleet size by motor fuel type;

$M$ - vehicle mileage;

$F$ - motor fuel consumption by type.

A detailed forecasting algorithm for the individual parameters of this motor fuel demand equation includes:

1. Projected car fleet size is calculated. We use the method applied by IEA (2011). This method determines the number of vehicles as an S-shaped function of the saturation level defined for each node or cluster and projected GDP.

2. Projected disposal of old vehicles. Historical disposal rates are extrapolated for the future by constructing a trend.

3. Total number of new vehicle sales in any given year is determined based on the total vehicle fleet and projected disposal rate.

To determine the structure of new vehicle sales by fuel type, we calculate the coefficients of attractiveness of vehicles by fuel types. This calculation depends on the following: the comparative cost of vehicle ownership, the availability of infrastructure, consumer preferences, technological development. "New vehicles" also include purchased vehicles previously used in other nodes.

Module 5 calculation algorithm:

1. The cost of vehicle ownership by fuel, is determined in Eq. 3:

$$
O P_{t}=\frac{V C}{L C}+M \times R \times F P
$$

where:

$t$ - year; 
$O P$ - annual cost of vehicle ownership;

$V C$ - typical vehicle cost by fuel type;

$R$ - fuel consumption for a run;

$L C$ - vehicle life for the node, given exogenously;

$M$ - average annual mileage of a vehicle by fuel type;

$F P$ - fuel price, set. The authors obtained it from the calculations made using the SCANER, see Makarov, Galkina, Grushevenko (2014).

2. The cost of vehicle ownership is ranked from the cheapest to the most expensive, costs of ownership are converted into coefficients.

3. Coefficients for infrastructure availability, which is critical in assessing demand for natural gas vehicles and electric vehicles, and consumer preferences for purchasing the vehicles by fuel type, are determined.

4. The final coefficient of vehicle attractiveness is calculated in Eq. 4, considering the total cost of ownership, the infrastructure availability factors and consumer preferences:

$$
K_{\text {attractive }, i}=\left\{\begin{array}{c}
\left(200-\frac{\mathrm{Kop}_{i}}{\mathrm{Kop}_{1}}\right) \times K_{\text {inf }} \times K_{\text {pop }}, \text { if }\left(\left(200-\frac{\mathrm{Kop}_{i}}{\mathrm{Kop}_{1}}\right) \times K_{\text {inf }} \times K_{\text {pop }}\right)>0 \\
N V \times 0.01 \%, \text { if }\left(\left(200-\frac{\kappa_{\text {op }}}{\mathrm{Kop}_{1}}\right) \times K_{\text {inf }} \times K_{\text {pop }}\right) \leq 0
\end{array}\right\}
$$

where:

$i$ - fuel type;

$K_{\text {attractive }, i}-$ attractiveness coefficient;

$K o p_{i}$ - coefficient reflecting the average annual cost of vehicle ownership operating on fuel i;

$\mathrm{Kop}_{1}$ - coefficient of average annual cost of vehicle ownership for the cheapest and the most attractive fuel type;

$K_{\text {inf }}$ - infrastructure availability coefficient;

$K_{\text {pop }}$ - consumer preferences coefficient;

$N V$ - sales of new vehicles.

In Module 4, the structure of new sales is obtained by a nonlinear optimization calculation method, based on the total number of new sales and attractiveness coefficients calculated in the Module 5.

Resulting numbers of future vehicles by fuel types, average fuel consumption and annual mileage make it possible to project demand for motor fuels in the road transport sector.

After reconciling the results from Module 2 and Module 4 in Module 6, a reconciliation of Module 1 results and adjusted Module 2 results is made within Module 7, providing the projected PP demand.

\section{PP demand forecast in Russia}

Assumptions for the Russian PP demand forecast were the following: GDP and population dynamics up to 2040 are from the forecast of the Russian Economic Ministry and Rosstat. The official projection of the Russian average annual GDP growth rates in 2014-2040 is 2,6\%, while during this period the population will decline by $11 \%$ compared to 2014. Car fleet size, structure and disposal rates statistics were taken from Autostat (Autostat, 2015). Average fuel consumption, vehicle cost and cost of their switching estimates were based on the market analyses, including car fleet structure analyses and assumptions on the potential for the future reduction of the specific fuel consumption for different types of vehicles (Makarov et al. 2013). 
Figure 2. Deviation of the total PP demand calculations, prepared using different forecasting methods, from the retrospective data.

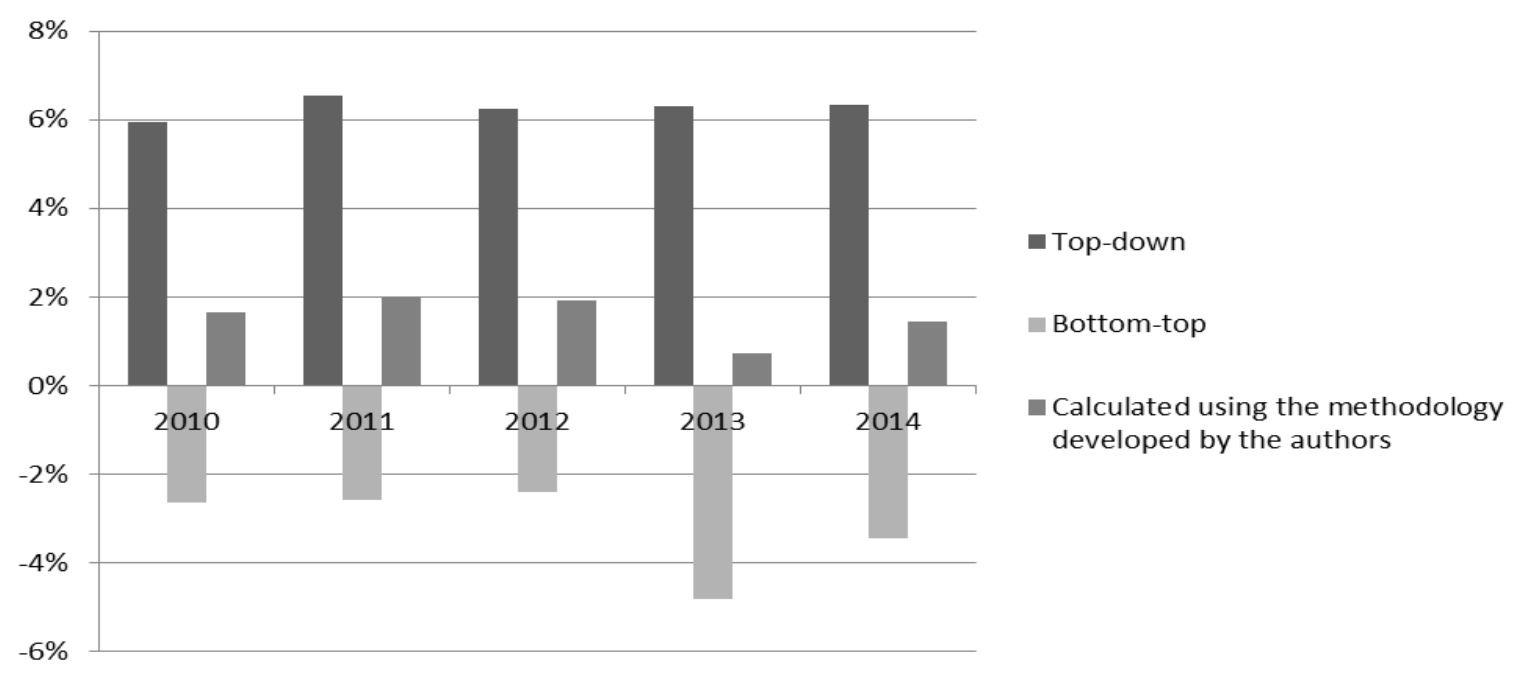

Figure 3. Projected Russian PP demand, calculated using different methodologies, including methodology developed by the authors.

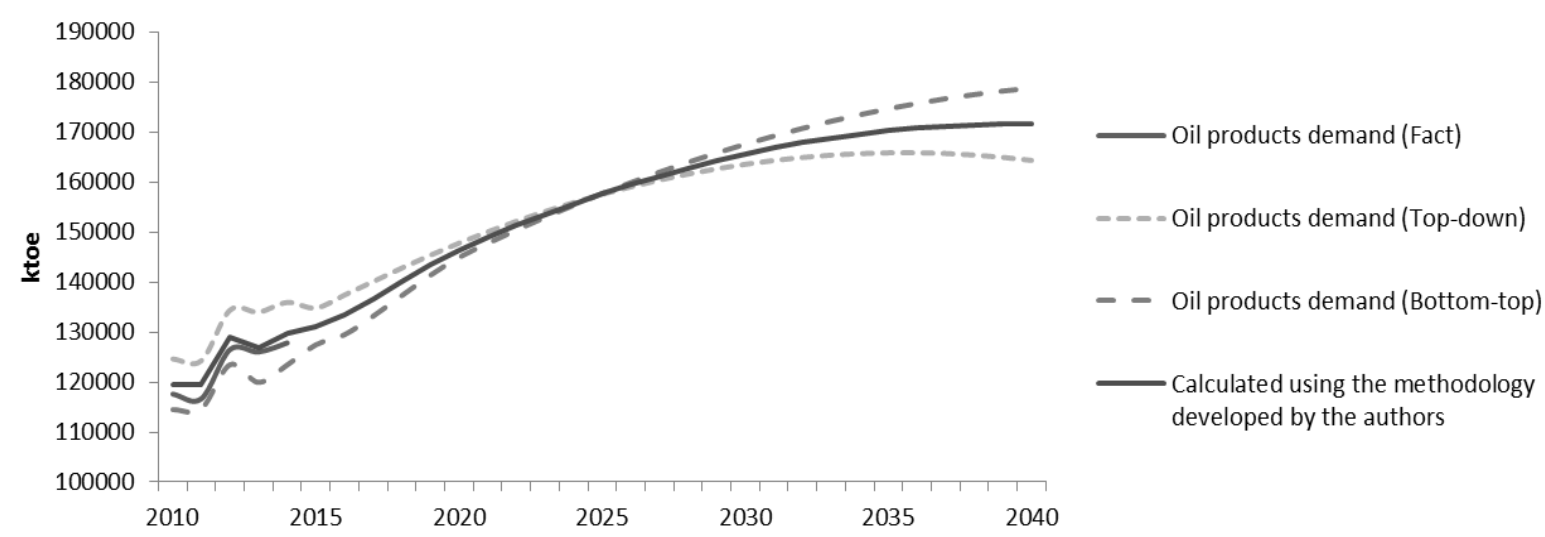

The proposed methodology proved to be more relevant, then the other approaches: as shown at Figure, results of the Modules 1 and 2 (which use only "top-down" approach, defining PP demand based only on GDP and population dynamics), tend to overestimate PP demand - in the retrospective period 2010-2014 their results were 6-7\% higher than the fact. For the future PP demand projections they create high expectations and stimulate overinvestment. On the other hand "bottom-top" approach alone (represented in Modules 4 and 5) tends to underestimate PP demand-by $2-5 \%$, as verification on the retrospective data has shown. This could lead to insufficient investments in the capacity expansion and PP deficit. At the same time combination and reconciliation of these two approaches «top-down» and «bottom-top», as suggested by the proposed methodology, which is taking place in Module 7, allows to minimize deviation of the results from the retrospective data to just 1-2\% (Figure ) and to obtain the most relevant results (Figure 3).

\section{Conclusions}

The developed methodology makes it possible to evaluate PP demand for various nodes (countries, regions within countries, countries, groups of countries). The modular structure of the methodology allows further improvement of calculation elements as additional information 
becomes available. Economic, demographic and technological indicators are considered in an integrated way. Calculations can be revised and mutually reconciled, providing for higher reliability of the forecast results. The methodology, developed by the authors, makes it possible to consider a wide range of scenarios, while incorporating changes in the various indicators in the calculations.

Acknowledgements. This study was performed with a grant from the Russian Science Foundation (project No. 14-19-01459).

\section{References}

Autostat, 2015. Automotive market in Russia, available at http://eng.autostat.ru/catalog/product/156/ (Accessed 1 September 2015).

Behrang M.A., Assareh E., Ghalambaz M., Assari M.R. and Noghrehabadi A.R. (2011) Forecasting future oil demand in Iran using GSA (Gravitational Search Algorithm), Energy, 36, 5649-5654.

Bhattacharyya S. and Timilsina G.R. (2009) Modeling energy demand of developing countries: are the specific features adequately captured?, Energy Policy, 38, 1979-1990.

Bouachera T. and Mazraati M. (2007) Fuel demand and car ownership modeling in India, OPEC Review XXXI, 31, 27-51.

Button K., Ndoh N. and Hine J. (1993) Modeling vehicle ownership and use in low income countries, Journal of Transport Economics and Policy, 27, 51-67.

Chai J., Wang S. and Guo J. (2012) Demand Forecast of Petroleum Product Consumption in the Chinese Transportation Industry, Energies, 5, 577-598.

Cheze B., Gastineau P. and Chevallier J. (2011) Forecasting world and regional aviation jet fuel demands to the mid-term (2025), Energy Policy, 39, 5147-5158.

Cleveland C.J., Kaufmann R.K. and Stern D.I. (2000) Aggregation and the role of energy in the economy, Ecological Economics, 32, 301-317.

Forouzanfar M., Doustmohammadi A., Hasanzadeh S. and Shakouri H. (2012) Transport energy demand forecast using multi-level genetic programming, Applied Energy, 91, 496-503.

Grigoriev, L. and Kurdin, A. (2013) Economic Growth and Demand for Energy, Ekonomicheskii zhurnal VSE, 3, 414-432.

Grushevenko, D. and Grushevenko, E. (2015) Countries grouping for PP demand forecasting using cluster analysis, Neft, Gaz i Biznes, 2, 23-26.

Grushevenko, E. and Grushevenko, D. (2012) Unconventional Oil Potential Tends to Change the World Oil Market, CSCanada Energy Science and Technology, 4, 68-74.

International Energy Agency (2014) Energy Technology Perspectives 2014, Paris.

International Energy Agency (2011) World Energy Model - Methodology and Assumptions, available http://www.iea.org/media/weowebsite/energymodel/WEM_Methodology_WEO20111.pdf (accessed 20 March 2015).

International Energy Agency (2014) World Energy Outlook, Paris.

Kugelevičius, J. and Kuprys, A. (2007) Forecasts of Petroleum Demand Transport, Transport, XXII, 9-13.

Makarov, A.A., Veselov, F.V., Eliseeva, O.A., Kulagin, V.A., Malakhov, V.A., Mitrova, T.A., Filippov, S.P. and Plakitkina, L.S. (2011) SCANER Super Complex for Active Navigation in Energy Research, ERI RAS, Moscow. 
Makarov, A., Galkina, A. and Grushevenko, E. (2014) Global Energy Markets Outlook up to 2040, MEMO Journal, 1, 3-20.

Makarov, A., Mitrova, T. and Grigoryev, L. (2013) Global and Russian Energy outlook to 2040, available at http://www.eriras.ru/data/290/eng (accessed 1 April 2015).

Makarov, A., Mitrova, T. and Grigoryev, L. (2014) Global and Russian Energy outlook to 2040, available at http://www.eriras.ru/files/2014/forecast_2040_en.pdf (accessed 1 April 2015).

Mitrova, T. and Galkina, A. (2013) Inter-fuel Competition, Ekonomicheskii zhurnal VSE, 3, 394-413.

Schremp, G., Bahreinian A. and Weng-Gutierrez, M. (2010) Transportation Energy Forecasts and Analyses for the 2009, Integrated Energy Policy Report, California Energy Commission, CEC-600-2010-002-SF.

Nakanishi T. (2006) Supply and Demand Analysis on PP and Crude Oils for Asia and the World KOMIYAMA, The Energy Data Modeling Center, The Institute of Energy Economy, Japan.

U.S. Department of Energy (2014), Transportation Demand Module of the National Energy Modeling System: Model Documentation, available at http://www.eia.gov/forecasts/aeo/nems/documentation/transportation/pdf/m070(2014). pdf (accessed 9 March 2015).

Wang, M., Huo, H., Johnson, L. and He, D (2006) Projections of Chinese Motor Vehicle Growth, Oil Demand, and CO2 Emissions through 2050, Transportation Research Record: Journal of the Transportation Research Board, 2038, 69-77.

World Energy Council (2011) Energy \& Mobility Background material report, London. 